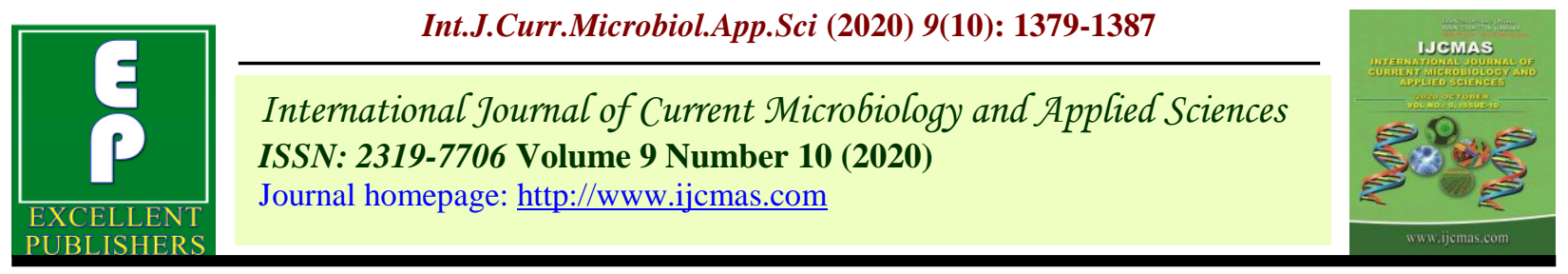

Review Article

https://doi.org/10.20546/ijcmas.2020.910.165

\title{
Advances in Sugarcane Peeling Mechanisation
}

\author{
S. K. Pandey ${ }^{1 *}$, P. K. Mishra ${ }^{1}$ and S. K. Pandey ${ }^{2}$ \\ ${ }^{1}$ Mahamaya college of Agricultural Engineering and Technology, Ambedkar Nagar-224122, \\ (ANDUAT, Kumarganj, Ayodhya), India \\ ${ }^{2}$ College of Agriculture, Kotwa, Azamgarh, 276001 (ANDUAT, Kumarganj, Ayodhya), India \\ *Corresponding author
}

\begin{tabular}{l} 
K e y w o r d s \\
$\begin{array}{l}\text { Sugarcane peeling } \\
\text { machine, Peeling, } \\
\text { Sugarcane, } \\
\text { Mechanisation, } \\
\text { Peeling efficiency }\end{array}$ \\
\hline Article Info \\
$\begin{array}{l}\text { Accepted: } \\
12 \text { September } 2020 \\
\text { Available Online: } \\
10 \text { October } 2020\end{array}$ \\
\hline
\end{tabular}

\section{Introduction}

The sugar cane family is made up of over 30 sugar cane varieties. Sugar cane is a perennial grass that thrives in hot, humid locations like Brazil and India. The sugar derived from sugar cane is used in syrups, juices, and molasses, but the rest of the plant can also be used in the production of environmentally friendly paper products.
Sugarcane is multipurpose crop that serves as source of sugar, juices, jaggery and various products for man and raw materials for industry. But prior to the process of machining process, some processing is required to remove the solid particles, spots and sludge on the cane. The processing of sugarcane strip for industrial or human use involves different operations of which peeling is a major one and cannot be neglected. Of all the unit operations involved in cane processing, several processes have been mechanized successfully. This study presents the features, prospects, performance evaluations and limitations of some sugarcane peeling machines in world like the fixed outer drum peeler, automated cane peeler, knife-edge type self-fed peeler, etc. Their peculiar advantages and operational parameters such as machine speed, output capacity, peeling efficiency and cane losses were evaluated. Aside from the manual ones, the ranges of the peeling efficiency and cane loss were recoded in range of $59.9-91.4 \%$ and 2-4\% respectively. As machine speed increased, the output capacity and cane loss increased while peeling efficiency decreased. Mechanization of this peeling process has the potential of encouraging growth in cultivation, cane utilization and improving the product quality of value-added products. The product quality, processing efficiency, minimum loss of cane and increased processing rate will be affected by improved sugarcane peeling process. 
such as cancer and cardiovascular diseases. Although the industrial production of sugarcane juice has a business potential, the selling of sugarcane juice cannot be expanded as expected owing to its rapid quality descent (Tagare et al., 2013).

As we know that sugarcane is source of $70 \%$ of world's sugar and sugarcane juice contain lots of contaminants which reduces health issues, so before the formation of sugar, juices are refined to remove many unwanted impurities using high dose of chemicals. So, peeling is the first process from harvest to processing which is a very important operation. It is a process in which upper layer of sugarcane is removed along with black spots, mud and impurities. In industrial production, suspended solids will be removed by means of adding chemical additives. But if the sugarcane surface processing can be done before refining sugar, it can reduce the content of sediment and rocks. It is a good way to reduce the concentration of the suspended solids in sugar cane juice, which can reduce the number of adding chemical additives. In the actual production, it is often through the sugarcane peeling to reduce content of sediment and rocks and it also can increase the quantity of sugarcane juice (Dehui, 2015).

\section{Problems in sugarcane peeling}

Sugarcane processing operations are often preceded by peeling which makes it a very important operation. Peeling is the first operation performed after the sugarcanes have been harvested and cleaned from debris. Problems presently encountered in sugarcane peeling include:

i. Peeling off of unacceptable percentage of useful flesh during mechanical peeling.

ii. Reduction in peeling efficiency with increased time and speed of operation. iii. Manual peeling is either slow, labour intensive or cost ineffective.

iv. Insufficient technical data on the engineering properties of canes required for the machine design as well as the crop and machine operational parameters needed for modelling and designing the peeling process.

In summary, problems encountered in peeling sugarcane arise from the fact that cane exhibit appreciable differences in weight, size and shape. There are also differences in the properties of the sugarcane peel which varies in thickness, texture and strength of adhesion to the cane flesh. A successful sugarcane peeler should, among other things, be efficient in removing the cortex of sugarcane without substantial loss of useful flesh.

\section{Mechanisation of Sugarcane peeling}

Mechanisation in the field of sugarcane was started in 1990. Srivastava and Singh (1990) made efforts to establish the mechanism suitable for de-trashing the whole cane. However, they reported that, at that time, an appropriate machine for successful mechanisation of this operation was not available. Sandhar (1995) showed that, for optimisation of the variables of the mechanical cleaner, the mill trash should not exceed $3 \%$ and maximum acceptable cane loss should be $2 \%$. This was based on the fact that, even in the manual cleaning of sugarcane, the trash percentage is more than 2\%. Lin (2009) reported that Sugarcane peeling was done using artificial way mostly in China, and its efficiency was recorded low. This was led to felt that there was need for a highly efficient sugarcane peeling machine for improving peeling production efficiency and reducing the peeling cost.

A major change in the process of peeling sugarcane came in 2012. When Yan et.al (2012) introduced a large-scale sugarcane 
stripper with an automatic feeding module, including automatic feeding module, cleaning leaves module, collecting module and control module, it changed the current sugarcane harvest mode in which they used the mature technology of mechanical engineering.

The mode of double stage carding was used for the input of the automatic feeding module shown in fig. 1. First, the sugarcane was placed on the working platform 1and, with the help of rotation of carding wheels 5 and 6 , it was transferred to conveyor belt 2 and then transfer belt 3 through the conveyor belt which was connected to the cleaning module. The cleaning leaves module includes the speed limit wheel, stripper wheel, stripper bar, and sugarcane as shown in fig. 2. With the help of the transmission system, the speed limiting wheel and the stripper wheels were doing a constant axis rotation. The stripper wheel was a two-cylinder shaped roller, making relative rotation. When the stripper was rotated at high speed, the sugarcane leaves were cleaned and they used several stripper wheel units for better peeling efficiency.

The collecting module mainly consists of two parts: collecting sugarcane leaves and collecting sugarcane. Sugarcane and leaves were moved by belts. Figure 3 shows the sketch of the collecting module.

In simple words, the sugarcane was collected by the transfer belt 5 of longitudinal movement, after the leaves had been cleaned. While sugarcane leaves were collected by the transfer belt 4 . They used modern control theory. The controller (Fig. 4) working together of automatic feeding module, cleaning leaves module and collecting module. The controller mainly controlled the feeding speed of the automatic feeding unit, the rotation rate of the stripper wheel, and the speed of the collecting unit.
Finally, if told, they just gave the idea that we should make a large-scale sugarcane stripper with automatic feeding machine so that we can change the harvest method. Similarly, the work of Tagare and Patil (2013), gave a significant change in the field of sugarcane peeling machine. They provided a base for commercial production of sugarcane peeling machine using locally available raw material at relatively low cost. Before feeding to main section of machine, firstly clean sugarcane by brushes to remove carbon spot and muds that were usually the part of sugarcane, then after this cleaning process sugarcane stalks were fed to peeling section. In peeling section, the peeling of sugarcane stalks was done by spring loaded blade assembly. The special advantage of this machine was of spring loading system. This facilitated the change of sugarcane peeling drum with the change of sugarcane stalks diameter as shown in fig. 5 .

Moreover, they tested the peeling efficiency of machine which was recorded 59.66\%. But this was considered to be significant achievement in the field of automisation of sugarcane peeling machine. A lot of changes took place in the peeling process over time, one such change was made by Ahmat et al., (2014), they proposed a new design to solve the peeling method by designing a new blade having curved cutting surface shown in fig. 6 installed with rollers to push in and out the sugarcane stalk in blade compartment shown in fig. 7.

To improve in the design of blade and for efficient cutting they conducted the compression test (Fig. 8). They suggested that, a better peeling system is needed in which stiffness of spring contributes better design mechanism better larger extent. Therefore, they recommend that $800 \mathrm{~N}$ stiffness should be consider while designing springs for peeling purpose of sugarcane. And 
they also pointed that stiffness of spring contributes to the correct selection speed to improve products result.

Given the difficulties in the sugarcane peeling process, a type of automatic sugarcane peeling machine was designed based on the motion controller by Dehui (2015). He explained that since sugarcane differs from other crops, its radial dimensions vary and always have curved shapes, normal blades cannot be applied. It is necessary to design blades according to the characteristics of sugarcane to meet the requirements of sugarcane peeling. So, he reported that a type of blade having eight cutting edges is shown in fig. 7 that would be made freely adjustable to his tool rod.

Fabricated sugarcane peeling machine made up of feeding part and cutting part. The proposed machine made up of two parts: Drive mechanism part (Fig. 8) and cutting part. The sugarcane peeling machine was mainly made of two part: feed part and cutting part and the feeding part was mainly composed of servo motor, rubber wheel and drive mechanism. Rubber wheel was used at the start of sugarcane machine. Rubber wheel was driven by fixed servo motor and the cane was driven by rubber wheel. At the both end (feed end and discharging end) rubber wheel driven by servo electric motor. Structure diagram is shown in fig. 9 .

Servo motor drives pulley which in turn drives gear which was connected to the pulley. The pulley and gear rotate at the same time. Though two gear meshing with two rubber wheel reverse rotate which drives cane to move forward rotate which drives cane to move forward. The connection between rubber wheel and body frame was elastic which basically incorporated different diameter of sugarcane. The most important part i.e. photoelectric switch was placed between feed rubber wheel and discharging rubber wheel. When these photoelectric switches detect the cane, send the signals to servo motor which drive rubber wheel to drive sugarcane.

Cutting part shown in fig. 10 was consists of squirrel cage rests where it supports elastic tool rod and blades. Elastic tool rod is fixed on the rest can be close to the blade. According to him the motion controller served as control core of machine and photoelectric switch served as detecting element shown in fig.11. Finally, this provided a new opening in the field of automation of sugarcane peeling. This developed system was useful in implementing automation of feeding, discharging and peeling at a commercial level also. According to them such developed system will replace manual labour, greatly improved production efficiency and cost. Hence, a great significance in sugarcane processing.

A small-scale sugarcane peeling machine was developed and evaluated by Yamani and Basiouny (2016), under three different type of peeling drum brush system, namely zig-zag, straight and spiral type with four peeling drums of speed in range of $3.53-9.18 \mathrm{~m} / \mathrm{s}$, three peeling drum of clearance $1.0-2.0 \mathrm{~cm}$ and three feeding rates 3 - 9 cans / min. Machine performed better peeling efficiency under zig-zag type peeling drum brush with peeling efficiency of $91.4 \%$ having minimum cane loss of $3.02 \%$ with production efficiency of $88.85 \%$ at the peeling drum speed of 9.18 $\mathrm{m} / \mathrm{s}$ with feeding rate of $3 \mathrm{cane} / \mathrm{min}$.

A new design of sugarcane peeling machine to reduce the total time required due to manual peeling and reduction in operator fatigue due to the tiresome peeling operation was proposed by Kadam et al., (2018). The proposed machine was expected to peel sugarcane at a faster rate without much fatigue. The proposed model of machine is shown in fig. 12. 
They explained their proposed model in which the peeling action takes place in orbital fashion. The fig. 12 above shows the conceptual diagram of the proposed concept. In this the sugarcane will be fed by rollers into the orbital drives, the orbital drive consists of brushes on the inner periphery as shown in the conceptual diagram (Fig. 12). Once the sugarcane was fed into the rollers, the rollers pull the sugarcane using the drive from the motors and fed into an orbital drive brush cleaner. As it moves across the orbital drive, the brush cleans the sugarcane on the outer surface thereby peeling it. After the sugarcane comes out of the orbital cleaner, the horizontal brush in front clean it thereby providing multistage cleaning in single pass. However, the cost of fabrication of this machine was more compared to the other concept as it included complex drive trains.

They evaluated the model and recorded the efficiency of $80 \%$ and was fabricated by using the available raw materials. The approximately linear sugarcane was loaded and conveyed by hand to the bearing attached with brushes. The overall performance of the machine was more efficient compared to already existing ones. The cost of production and maintenance was relatively cheap. The following conclusions can be drawn from this review of sugarcane peeling machines.

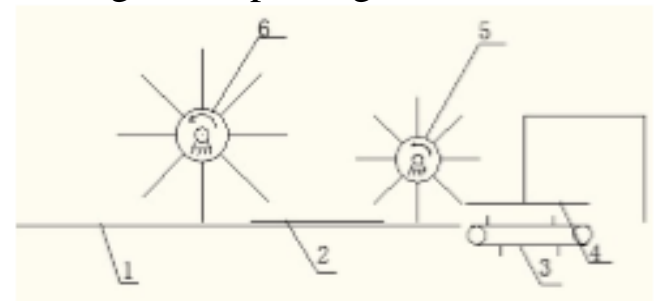

The schematic diagram of the automatic feeding module, 1: Working platform; 2: Conveyer; 3 : Transfer belt; 4: Barrier plate; 5: Carding wheel; 6: Carding wheel

Fig.1 Feeding module
The machines developed so far face problems of high cane losses and moderate peeling efficiency, meaning that the peel is not removed properly or completely, mainly due to the high variability of the cane size and thickness. They required hand trimming to complete the process.

Aside of the manual operated ones, the operating speeds of the other sugarcane peeling machines ranged from 100-1440 rpm.

The machine production efficiency was ranged from $65.17 \%-88.85 \%$.

The maximum peeling efficiency, the minimum cane stalks losses, output capacity and the lowest percentage of the peel retention on peeled stalks were $91.40 \%$, $3.02 \%, 200$ stalk per hour and $2.46 \%$, respectively. However, the peeling efficiency ranged from 59.66- 91.4\%.

Most of the peeling attachments developed are for single peeling and require multiple passes. Hence, it is not efficient. Also, the research work available as well as data available on the current topic is very less or not existing. Thus, this is the topic of innovation in the field of sugarcane peeling attachment/machine.

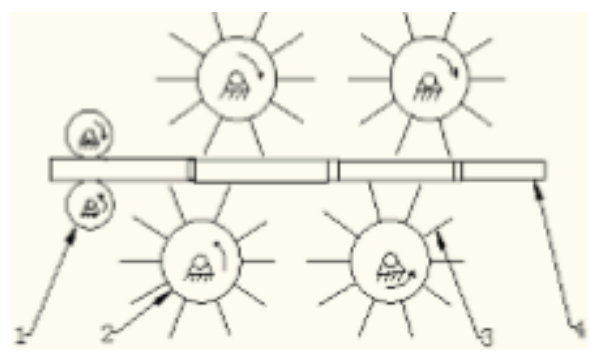

The schematic diagram of the cleaning leaves module, 1: The speed limiting wheel; 2: The stripper wheel; 3 : The stripper bar; 4: Sugarcane

Fig.2 Cleaning module 


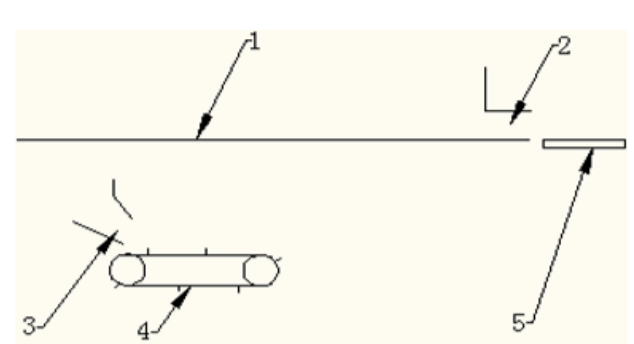

The schematic diagram of the collecting module, 1 : The region of cleaning leaves; 2: The exit of sugarcane; 3: The exit of sugarcane leaf; 4: Transfer belt; 5 : Transfer belt of longitudinal movement

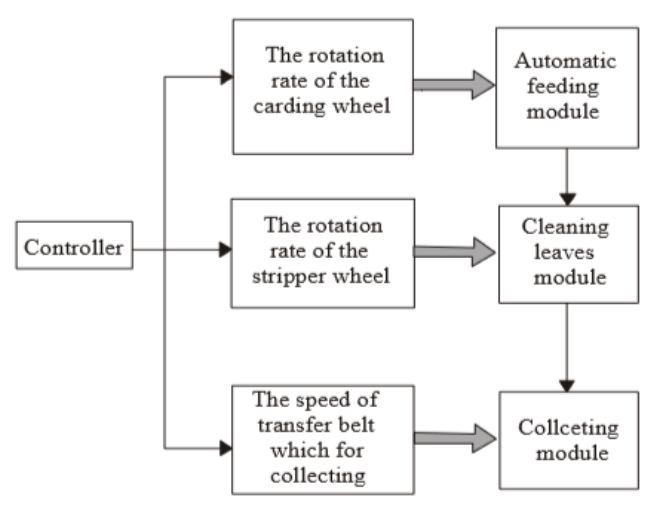

Fig.4 Control module

Fig.3 Collecting module

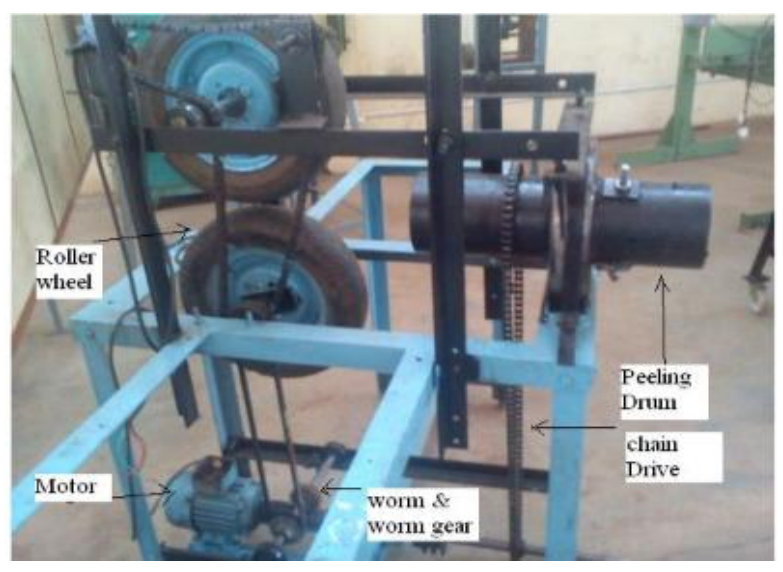

Fig.5 Sugarcane peeling machine

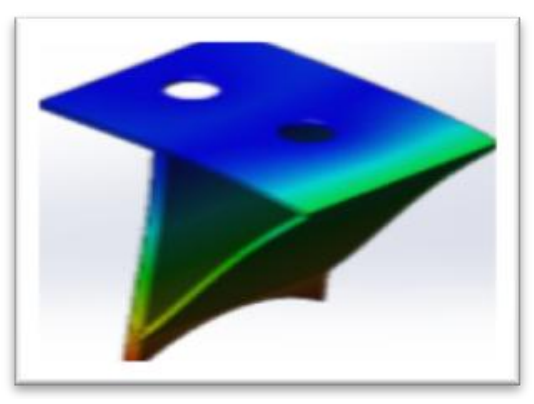

Fig.6 cutting blade

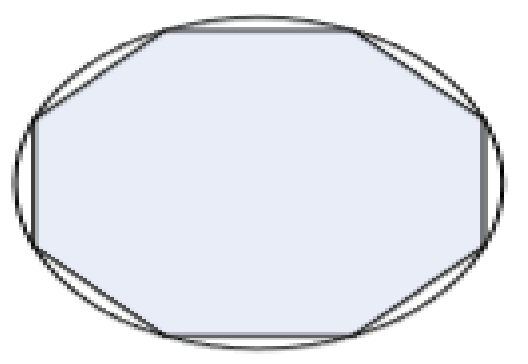

Fig.7 Blade design 


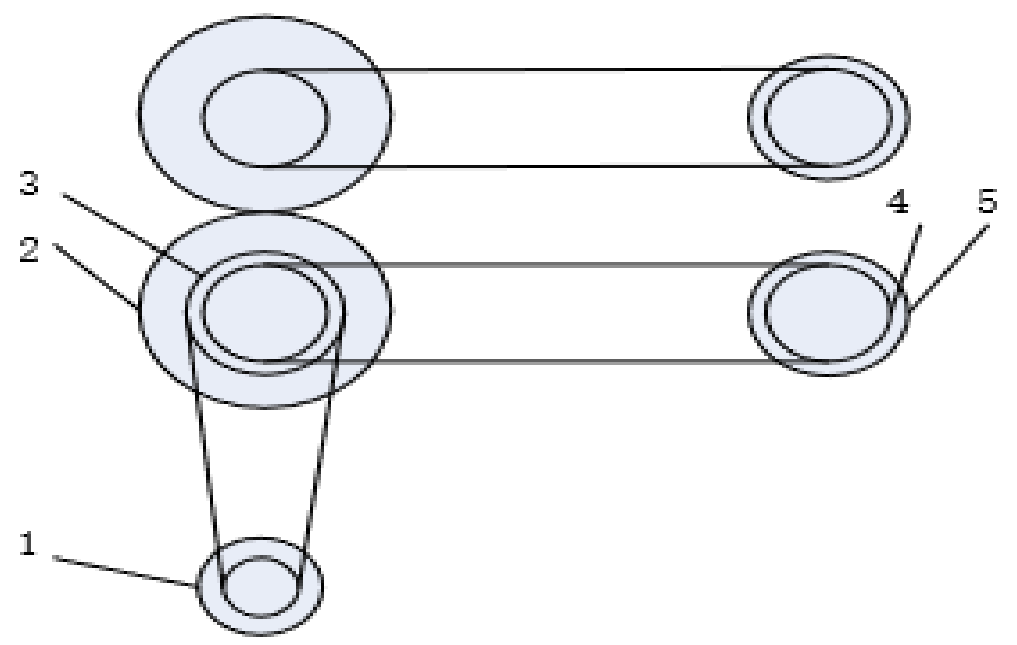
1. Bervo motor
2. Gear
3. Pulley 1
4.Pulley 2
5. Rubler rhee1

Fig.8 Drive mechanism

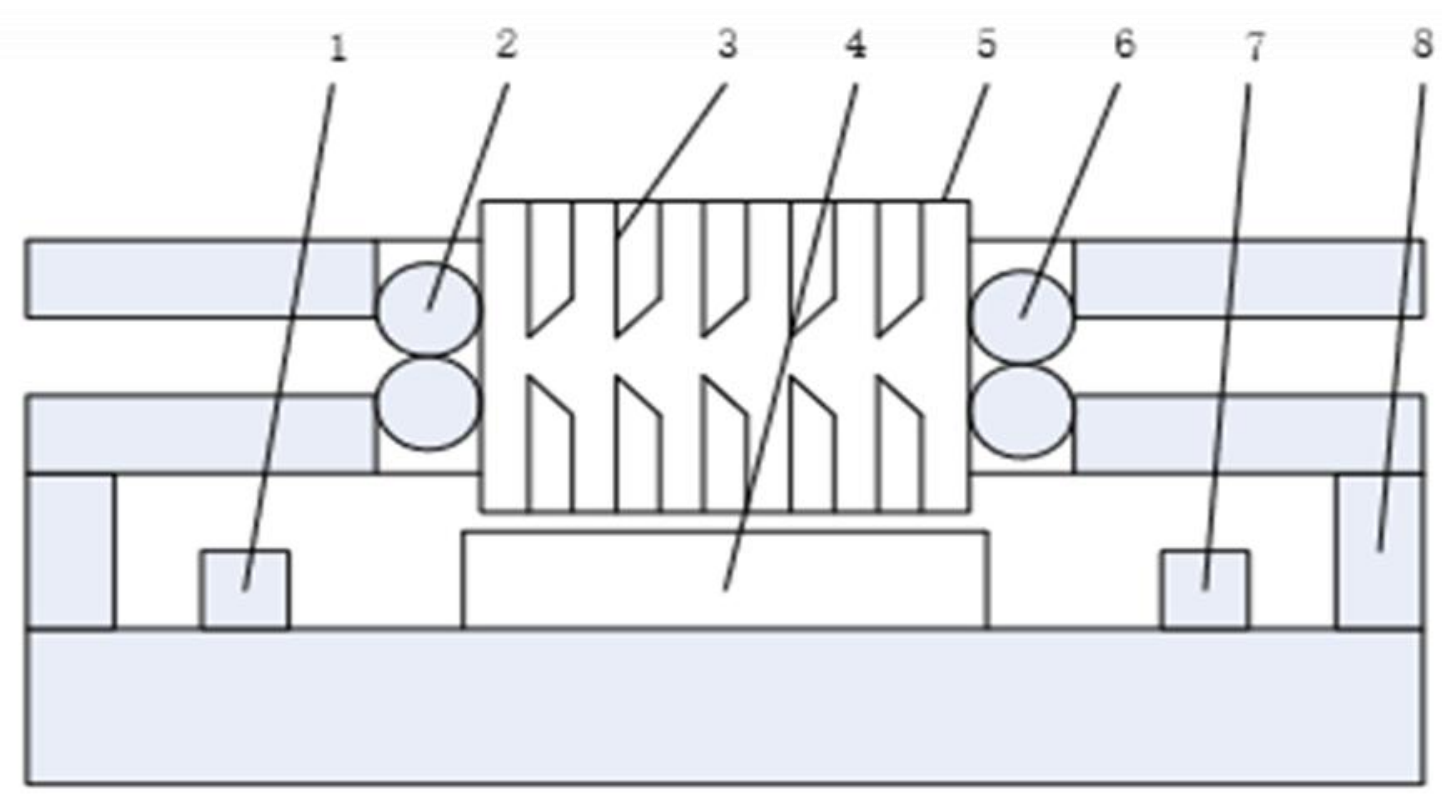
1. Feed motor
2. Feed rubber wheel
3. Blades
4. Storage box
5. Squirrel cage rest
6. Discharging rubber wheel

\section{Discharging motor 8. body frame}

Fig.9 Structure diagram 


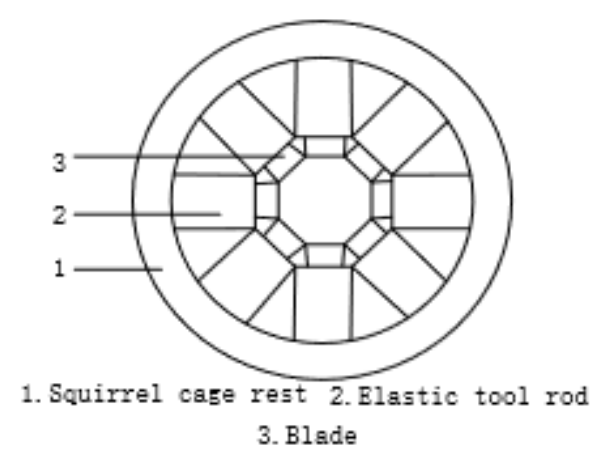

Fig.10 Cutting part

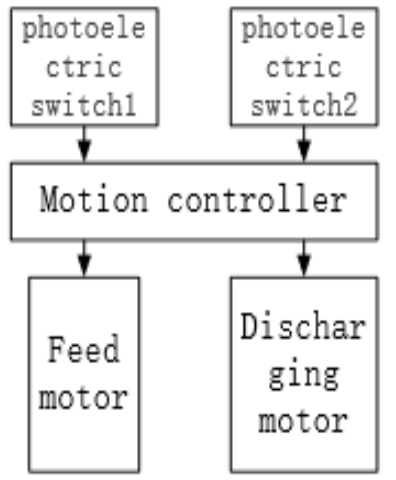

Fig.11 Motion controller

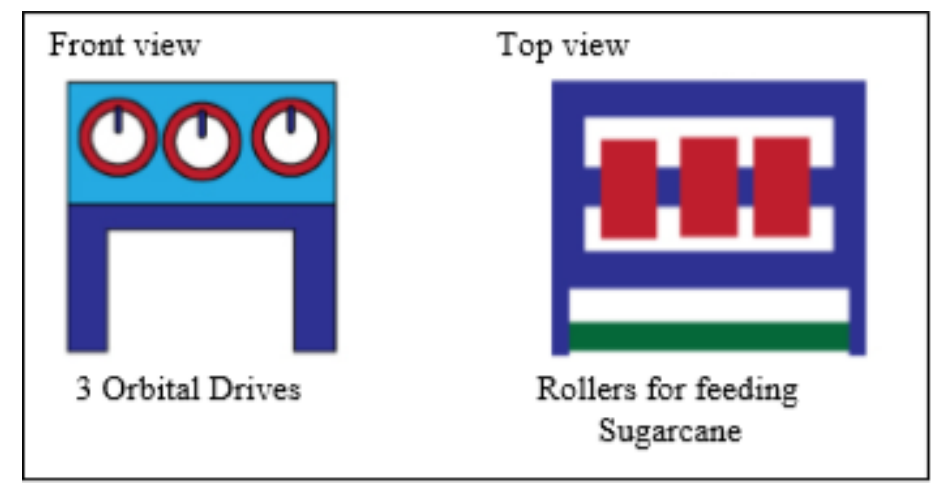

Fig.12 Conceptual diagram of machine

\section{References}

Ahmat, A.M.M., Hisyamudin, N.N. and Masrol, S.R. 2014. Sugarcane bark/skin peeling machine. International Integrated Engineering Summit (IIES),
1-4 December.

Anonymous, 2020a. A website http://www.shodhganga.inflibnet.ac.in is visited on 18/02/2020.

Anonymous 2020b. A website http://ask.learncbse.in is visited on date 
$18 / 02 / 2020$.

Dehui, Z. 2015. Design of sugarcane peeling machine based on motion controller. Advance Journal of Food Science and Technology, 7(10): 824-826.

Jiaxiang L., Wenjie Y and Jiaping L. 2012. The Large-Scale Sugarcane Stripper with Automatic Feeding, Advance Journal of Food Science and Technology, 4(14): 2183-2185.

Kadam, S.J., Suter, S., Shinde, P., and Shelke, K. 2016. Design and Fabrication of Sugarcane Peeling Machine, Journal Tech. Innovation. Brand, 87793-03-3.

Lin, H. 2009. The small sugarcane peeling machine, Journal Tech. Innovation. Brand, 57(2): 80.

Sandhar, N. S. 1995. Investigation on the mechanics of sugarcane cleaner. Unpublished Ph. D. thesis, Dept. of farm power and machinery. Punjab Agric. Univ., Ludhiana, India.

Srivastava, A. C. and Singh K. 1990. Development of power drawn sugarcane de-trasher. AMA 21(2): 49-52.

Tagare, V.S., Patil, V.B., Talaskar, S.P. and Wader, S.D. 2013. Design and manufacturing of sugarcane peeling machine. Int Journal of Advanced Scientific and Technical Research, 3(3):70-83.

Yamani, El. A.E. and Basiouny, M.A. 2016. Performance evaluation of new sugarcane peeling machine prototype. Journal. Soil Sci. and Agric. Eng. 7(4): 289298.

\section{How to cite this article:}

Pandey, S. K., P. K. Mishra and Pandey, S. K. 2020. Advances in Sugarcane Peeling Mechanisation. Int.J.Curr.Microbiol.App.Sci. 9(10): 1379-1387.

doi: https://doi.org/10.20546/ijcmas.2020.910.165 